\title{
Periareolar Augmentation Mastopexy with Interlocking Gore-Tex Suture, Retrospective Review of 50 Consecutive Patients
}

\author{
Johnny Franco ${ }^{1}$, Emma Kelly ${ }^{2}$, Michael Kelly ${ }^{1}$ \\ ${ }^{1}$ Miami Plastic Surgery, Department of Surgery, Division of Plastic Surgery, Florida International University, Herbert Wertheim College of \\ Medicine, Miami, FL; ${ }^{2}$ Vanderbilt University, Nashville, TN, USA
}

Background Periareolar Augmentation Mastopexy is one of the most challenging operations in plastic surgery. Problems with scar quality, areolar widening, and distortion are frequent problems that interfere with a predictable result.

Methods A retrospective review was performed on fifty consecutive patients who underwent a periareolar augmentation mastopexy with the interlocking approach. Of the 50 patients, 30 had both preoperative and postoperative photographs and were the basis of the study.

Results The age of the patients ranged from 19 to 56 years with the average age being 39 years. The postoperative follow-up averaged 9.5 months and the implants averaged $316 \mathrm{~mL}$. There were no deaths, pulmonary embolism, deep vein thrombosis, or infected implants. Four patients had complications following surgery for an overall complication rate of $13 \%$. Two patients developed an infected Gore-Tex suture. Two of these complications were treated with revision surgery. Five patients required reoperation for an overall reoperative rate of 16\% (one patient was converted to a full mastopexy).

Conclusions As a result of this retrospective study, we have found the interlocking approach to periareolar augmentation/mastopexy to be a safe and reliable operation.

Keywords Mammaplasty / Breast implantation / Cosmetic technique
Correspondence: Johnny Franco Miami Plastic Surgery, Department of Surgery, Division of Plastic Surgery, Florida International University, Herbert Wertheim College of Medicine, Suite 903-E, 8940 North Kendall Drive, Miami FL, 33176, USA TEL: +1-305-595-2969 Fax: +1-305-595-6491

This article contains supplemental Video S1.

This article was presented as a poster at the Aesthetic Meeting April 13-15th, 2013 in New York, USA.

No potential conflict of interest relevant to this article was reported.

Received: 12 Jun $2014 \bullet$ Revised: 23 Sep 2014 • Accepted: 23 Sep 2014

pISSN: 2234-6163 • elSSN: 2234-6171 • http://dx.doi.org/10.5999/aps.2014.41.6.728 • Arch Plast Surg 2014;41:728-733

\section{INTRODUCTION}

Periareolar Augmentation Mastopexy is one of the most challenging operations in plastic surgery. While the cosmetic result may occasionally be spectacular, many surgeons find it difficult to achieve consistently good results. Problems with scar quality, areolar widening, and distortion are frequent problems that interfere with a predictable, superior result.

Gruber and Jones [1] pioneered and described the first periareolar augmentation mastopexy in 1980. Although their ap- proach was an attractive concept in that it limited the scar to the periareolar region, the technique was subsequently criticized for problems with areola distortion and scar widening. In 1990, Benelli [2] described the "Round Block" technique of periareolar mastopexy which added a permanent circumareolar "purse string" stitch designed to limit distortion and widening of the areola. While Benelli's innovation was an improvement, it did not completely resolve these problems. Subsequent authors have also modified suture materials and purse string methods in an attempt to minimize those problems [3-14]. Spear et al. [15] 
also developed guidelines to the concentric mastopexy, which he revisited 10 years later. These articles were aimed at decreasing the complications and revisions needed with the periareolar mastopexy augmentation by creating guidelines for surgeons contemplating these procedures.

In 2007, Hammond et al. [8] introduced a new approach to the technique of periareolar augmentation mastopexy by adding an interlocking Gore-Tex suture (Gore-Tex, W.L. Gore and Associates, Flagstaff, AZ, USA). He theorized that the traditional Benelli purse-string technique created a significant amount of outward force within the superficial dermis of the areola and periareolar skin. It was this outward tension that caused some patients treated with the circumareolar approach to develop widening of the areola and scar. Hammond modified Benneli's technique so that it ran not only around the perimeter of the outer wound edge but also attached to the areola itself. This change allowed an even distribution of tension across the wound by "locking" the outer purse-string suture with the inner areolar edge in an interlocking pattern. He theorized that this closure would be strong beyond the outer superficial level, oppose the outward force generated in the traditional circumareolar technique, and result in less scar widening and areolar distortion.

Hammond's report described 3 patients treated with the interlocking purse string method. Since that initial paper, there have been no large series published to analyze the results of the interlocking technique and to see whether or not it truly improves outcomes. The purpose of this retrospective investigation is to analyze results compiled from 50 consecutive patients who underwent a periareolar augmentation mastopexy using the interlocking approach.

\section{Fig. 1. Patient 1}

Intraoperative view of the interlocking Gore-Tex Suture.

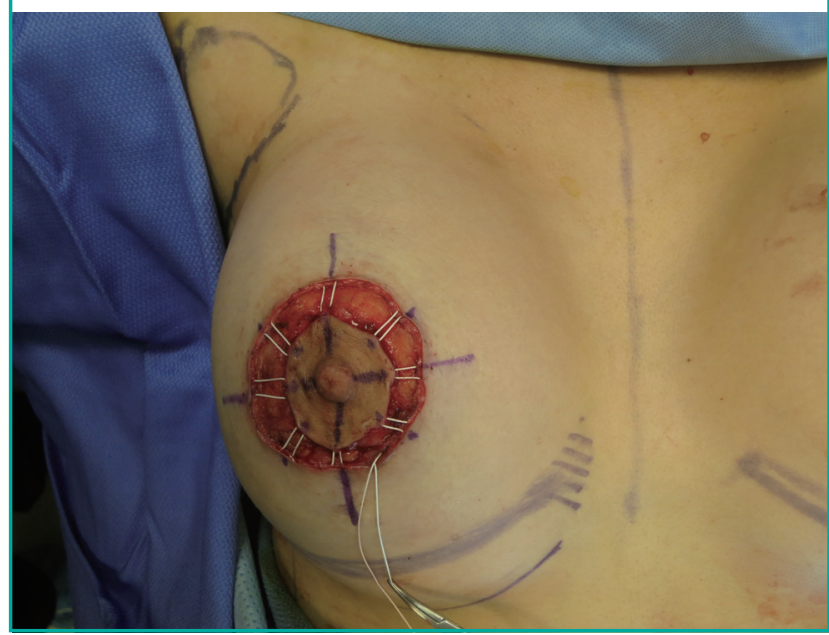

\section{METHODS}

A retrospective review of 50 consecutive patients was completed to evaluate the outcomes of the periareolar mastopexy augmentation using the interlocking Gore-Tex suture technique (Fig. 1). While the technique is well described in Hammond et al.s [8] original article, we have included a video to give a step-by-step approach to the technique (Supplemental Video S1). All of the patients were treated with this technique by the senior author, between March of 2009 and February 2012. Patients were not compensated for their participation in this study. Written consent was obtained from all patients for use of their data and photographs. An extensive literature review was conducted as well.

Chart review was undertaken to ascertain demographics, surgical indication, and degree of ptosis, implant size, postoperative complications and reoperative rates for the group. Only patients that had preoperative and postoperative photos were included in the study for evaluation, this left 30 patients in the review. Thus the basis of the analysis will calculated from the $30 \mathrm{pa}-$ tients as twenty patients did not have before and after pictures available to review (Table 1).

\section{RESULTS}

All patients were females exhibiting micromastia and ptosis. The average age of the patients was 39 and ranged from 19 to 56 years. Twenty-three patients underwent primary surgery whereas five patients received an implant exchange, one mastopexy augmentation after a breast reduction and one mastopexy revision with augmentation (Figs. 2-5). Four patients exhibited grade I ptosis, 20 patients exhibited grade II ptosis and 6 patients exhibited grade III ptosis, according to the Regnault Scale. The postoperative follow-up periods ranged from 2 to 34 months. The overall average follow-up period was approximately 9.5 months. The implants ranged in size from 125 to $465 \mathrm{~mL}$ with an average implant size of $320 \mathrm{~mL}$. Post-operative photographs were routinely taken at 3 months after surgery. Postoperative photographs were available for comparison in 30 patients and served as the basis for analysis of this study. In addition, long-term photos (greater than 1 year or longer) were obtained in 12 cases.

Table 1. Patients per each grade of ptosis

\begin{tabular}{|lcc|}
\hline Grade & Patients & Percent (\%) \\
\hline Grade I ptosis & 4 & 13 \\
Grade II ptosis & 20 & 66 \\
Grade III ptosis & 6 & 20 \\
\hline
\end{tabular}




\section{Fig. 2. Patient 2, 34-year-old}

(A) Preoperative image. (B) Postoperative image.
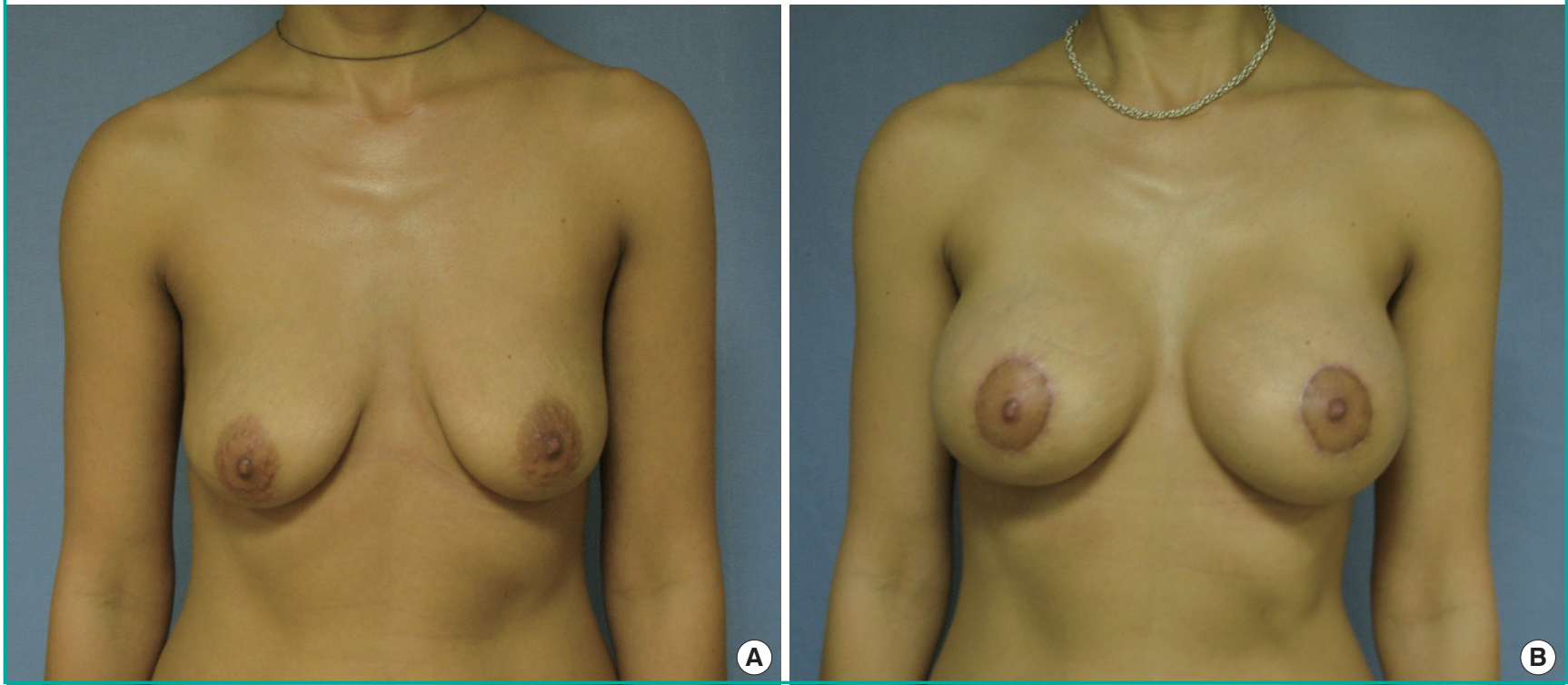

Fig. 3. Patient 3, 38-year-old

(A) Preoperative image. (B) Postoperative image.
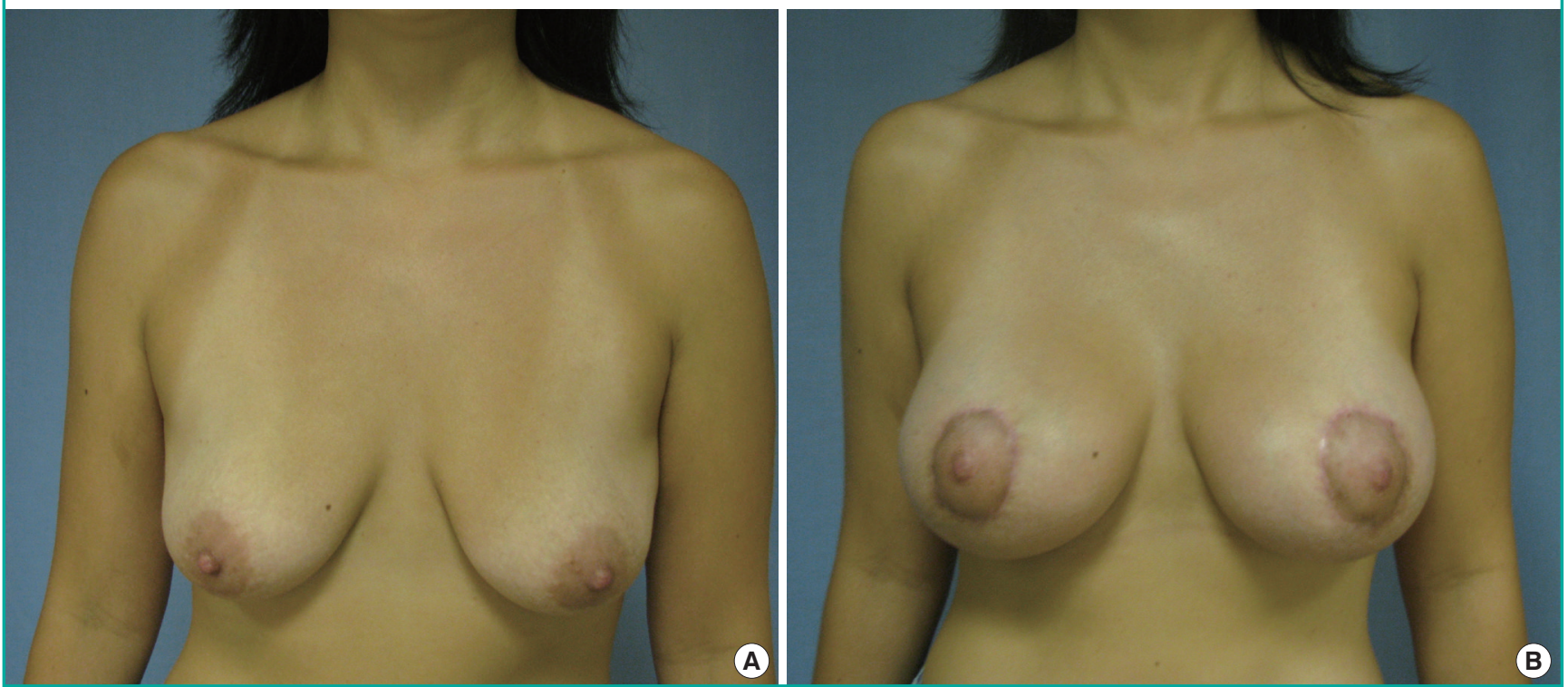

There were no deaths, pulmonary embolisms, deep vein thrombosis, or infected implants. There were four postoperative complications. Two were infected Gore-Tex sutures requiring removal under local anesthesia. The third was a case of allergic dermatitis of unknown etiology that resolved with topical steroids. The fourth was a patient with implants asymmetry that required surgical intervention. Five patients required reoperation for a $16.6 \%$ $(5 / 30)$ reoperative rate. Two of the five reoperations required general anesthesia. One was done for a patient who wanted more lift and was converted from a periareolar mastopexy to a full mas- topexy. The second reoperation done under general anesthesia was done to correct implant asymmetry. The remaining three reoperations were minor and done under local anesthesia. Two of those reoperations were the Gore-Tex suture removal listed above. One of those patients with Gore-Tex suture removal required a subsequent revision under local anesthesia for a small areolar distortion. The other patient with Gore-Tex suture removal elected not to have a revision (Table 2). 
Fig. 4. Patient 4, 33-year-old

(A) Preoperative image. (B) Postoperative image.
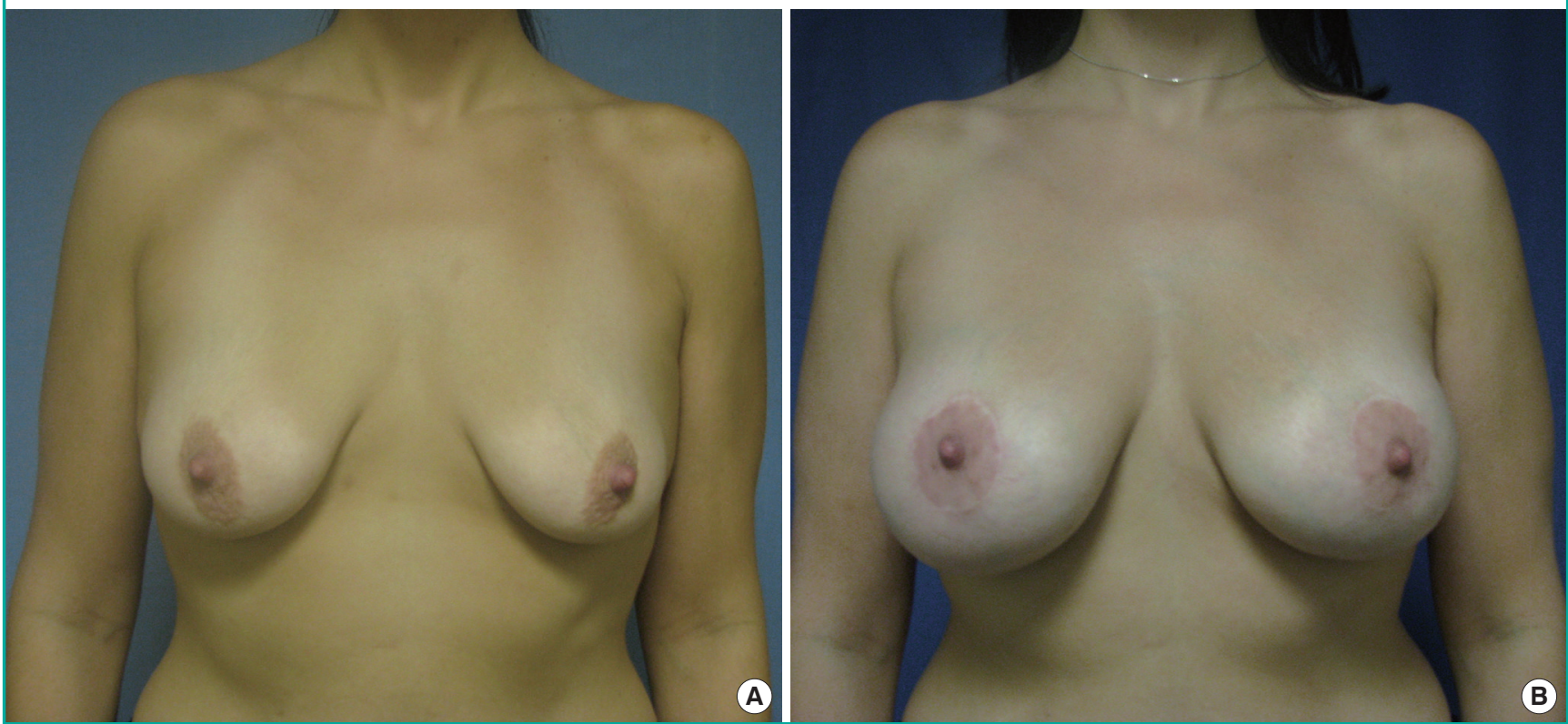

Fig. 5. Patient 5, 31-year-old

(A) Preoperative image. (B) Postoperative image.

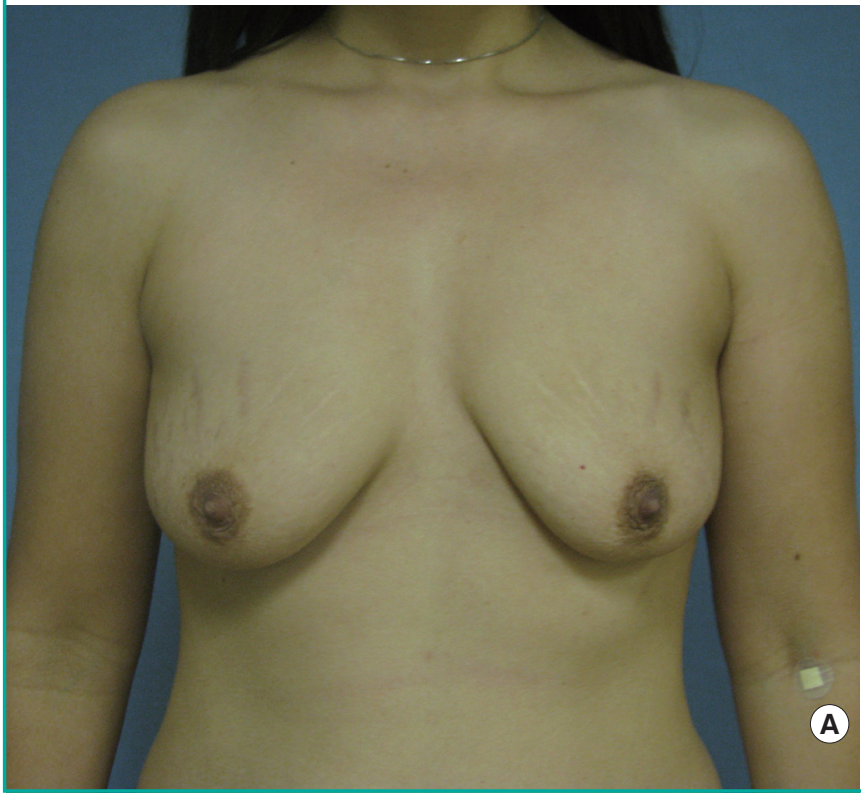

Table 2. Reoperation per category

\begin{tabular}{|lll|}
\hline $\begin{array}{l}\text { Reason for } \\
\text { reoperation }\end{array}$ & \multicolumn{1}{c|}{ Description } & Patients \\
\hline Gore-Tex & Two infected sutures & $6 \%(2 / 30)$ \\
Breast related & Allergic dermatitis & $3 \%(1 / 30)$ \\
Implant & Breast asymmetry & $3 \%(1 / 30)$ \\
Aesthetic & $\begin{array}{c}\text { Conversion to a full mastopexy-patient } \\
\text { requested further lift }\end{array}$ & $3 \%(1 / 30)$ \\
\hline
\end{tabular}

\section{DISCUSSION}

Despite the fact that the periareolar augmentation mastopexy was first described in 1980, there has been very little objective analysis of the procedure. Many surgeons continue to find this procedure challenging as noted by Spear [11]. Studies of large numbers of patients treated with different periareolar augmentation mastopexy techniques would be helpful for surgeons to de- 
termine which technical variations consistently produces the best results and the fewest complications. Unfortunately, these series don't exist. Most of the literature is comprised of case reports which describe 1-4 patients treated via the Benelli approach and it is unclear if these are the author's best results or a typical outcome. We could find only three published papers that focused exclusively on a large series of patients treated via periareolar augmentation mastopexy. These consist of the original paper by Gruber and Jones [1] in 1980, which described 13 patients, the series by Puckett et al. [13] in 1984, which described their experience with 26 patients and a crescentric approach, and the recent paper by Gonzalez [16] which described 28 patients and the periareolar augmentation mastopexy technique. None of these surgeons employed the interlocking technique. Hammond et al. [17] presented a report with 25 patients in which he used the interlocking technique at the 2005 American Society of Plastic Surgeons meeting but that data has never been published.

In addition to those papers focusing exclusively on periareolar augmentation mastopexy, there have been three large series, which grouped together all types of augmentation mastopexy patients. These papers included periareolar augmentation mastopexy patients as a subset of a larger augmentation mastopexy groups $[16,18,19]$. In Spears paper; he mentioned using the interlocking technique in some patients but did not separate out those results. Nonetheless, his study showed that $57 \%$ of his complications occurred in the circumareolar group, confirming the difficulty that many surgeons have with this approach. In Steven's group of augmentation mastopexy patients, his second leading cause of complications was the circumareolar approach. His revision rate was $27 \%$ for the circumareolar patients which were nearly twice as high as the rate for all types of augmentation mastopexy patients. He did not mention the interlocking technique. Calabrese also looked at a large group of all types of augmentation mastopexy patients, again including the circumareolar approach as a subset consisting of 66 patients [18]. He did not separate complications in the circumareolar subset from the augmentation mastopexy group as a whole, but his overall reoperation rate was $23.2 \%$. We could find no published report with a series of periareolar augmentation patients who were treated with the interlocking technique, except for Hammond's series of 3 . In our study, 50 consecutive patients were treated with the interlocking approach for periareolar augmentation mastopexy and their results were retrospectively reviewed.

Our study analyzed the patients based on their demographics, cosmetic results and complications. The patients' age, primary versus secondary surgery status, implant size and fill all seem to reflect what one would encounter in a standard cosmetic prac- tice and were similar to previously published reports. The review evaluated patients for complications and reoperation rate in attempt to establish the safety and reliability of the procedure.

Our complication rate for problems requiring revision surgery was $16.6 \%$ (5/30) patients. Two of those reoperations required general anesthesia, the other three were done under local. Complication rates for Wise pattern augmentation mastopexy have reoperative rates from $14.6 \%$ to $22.9 \%$. Our reoperative rate was at the low end of that range. It is difficult to draw conclusions about how the interlocking circumareolar technique compares to other augmentation mastopexy techniques, however our complication rate seems to better than or equal to previously published data.

Before changing to the interlocking technique in 2009, our approach was to use a circumareolar Gore-Tex suture around the perimeter of the outer wound as described by Benelli [2]. The video demonstrates visually how the interlocking approach is performed and how the nipple areolar complex can be precisely positioned.

Previous studies of the periareolar approach to augmentation mastopexy have been limited by their reliance on either single case reports or small numbers of patients analyzed. As a result of this retrospective study, we have found the interlocking approach to periareolar augmentation/mastopexy to be a safe and reliable operation. Future analysis of patients treated with periareolar augmentation mastopexy should include large numbers of patients and objective criteria for analysis the aesthetic result as well as the safety so that more definitive conclusions may be drawn. In the future direct comparison of other methods should also be done to be able to directly compare the results.

\section{REFERENCES}

1. Gruber RP, Jones HW Jr. The "donut" mastopexy: indications and complications. Plast Reconstr Surg 1980;65:34-8.

2. Benelli L. A new periareolar mammaplasty: the "round block" technique. Aesthetic Plast Surg 1990;14:93-100.

3. Dinner MI, Artz JS, Foglietti MA. Application and modification of the circular skin excision and pursestring procedures. Aesthetic Plast Surg 1993;17:301-9.

4. Ersek RA, Ersek SL. Circular cinching stitch. Plast Reconstr Surg 1991;88:350-2.

5. Mottura AA. Periareolar mastopexy and augmentation. Aesthet Surg J 2007;27:450-8.

6. Erol OO, Spira M. A mastopexy technique for mild to moderate ptosis. Plast Reconstr Surg 1980;65:603-9.

7. Rohrich RJ, Thornton JF, Jakubietz RG, et al. The limited scar mastopexy: current concepts and approaches to correct 
breast ptosis. Plast Reconstr Surg 2004;114:1622-30.

8. Hammond DC, Khuthaila DK, Kim J. The interlocking Gore-Tex suture for control of areolar diameter and shape. Plast Reconstr Surg 2007;119:804-9.

9. Baran CN, Peker F, Ortak T, et al. Unsatisfactory results of periareolar mastopexy with or without augmentation and reduction mammoplasty: enlarged areola with flattened nipple. Aesthetic Plast Surg 2001;25:286-9.

10. Spear SL, Low M, Ducic I. Revision augmentation mastopexy: indications, operations, and outcomes. Ann Plast Surg 2003;51:540-6.

11. Spear S. Augmentation/Mastopexy: "Surgeon, Beware”. Plast Reconstr Surg 2003;112:905-6.

12. Elliott LF. Circumareolar mastopexy with augmentation. Clin Plast Surg 2002;29:337-47.

13. Puckett CL, Meyer VH, Reinisch JF. Crescent mastopexy and augmentation. Plast Reconstr Surg 1985;75:533-43.
14. Stevens WG, Freeman ME, Stoker DA, et al. One-stage mastopexy with breast augmentation: a review of $321 \mathrm{pa}-$ tients. Plast Reconstr Surg 2007;120:1674-9.

15. Spear SL, Kassan M, Little JW. Guidelines in concentric mastopexy. Plast Reconstr Surg 1990;85:961-6.

16. Gonzalez R. The PAM method--periareolar augmentation mastopexy: a personal approach to treat hypoplastic breast with moderate ptosis. Aesthet Surg J 2012;32:175-85.

17. Hammond DC, Khuthaila DK, Kim J. The interlocking Gore-Tex suture for control of areolar diameter and shape. Plast Reconstr Surg 2007;199:804-9.

18. Calobrace MB, Herdt DR, Cothron KJ. Simultaneous augmentation/mastopexy: a retrospective 5-year review of 332 consecutive cases. Plast Reconstr Surg 2013;131:145-56.

19. Spear SL, Boehmler JH 4th, Clemens MW. Augmentation/ mastopexy: a 3-year review of a single surgeon's practice. Plast Reconstr Surg 2006;118:136S-147S.

Supplemental Video S1. Periareolar mastopexy augmentation video.

Supplemental data can be found at: http://e-aps.org/src/sm/aps-41-728-s001.mov 